\title{
POTENCIAL PEDAGÓGICO DO APLICATIVO WHATSAPP NO ENSINO DE BIOLOGIA: PERCEPÇÕES DOS PROFESSORES: PERCEPÇÕES DOS PROFESSORES
}

\author{
PEDAGOGICAL POTENTIAL OF THE APP WHATSAPP IN THE BIOLOGY TEACHING: \\ TEACHERS' PERCEPTIONS
}

\section{POTENCIAL PEDAGÓGICO DEL WHATSAPP EN LA ENSEÑANZA DE LA BIOLOGÍA: PERCEPCIONES DE LOS PROFESORES}

\begin{abstract}
RESUMO
Na cibercultura, o advento de dispositivos móveis mudou as formas de comunicação e interação. Conjuntamente com estes dispositivos, iniciativas alternativas ao ensino tradicional vêm sendo tomadas para atos de ensinar mais dialógicos e respeitando a realidade cultural que estamos vivendo, ligando assim espaços formais aos informais numa ação contínua de ensinar e aprender. Assim, o papel do professor e a ação de ensinar ganham espaços como aplicativos de comunicação de dispositivos móveis, como o Whatsapp, explorando suas múltiplas telas, tecendo novos caminhos para se aproximar da realidade dos estudantes. Neste contexto, o objetivo deste estudo foi analisar o potencial pedagógico do Whatsapp no ensino de Biologia. A hipótese do estudo foi que o aplicativo possui potencialidade pedagógica para o ensino de assuntos específicos desta disciplina em diferentes contextos e espaços. Dois professores de Biologia participaram do estudo. Utilizamos entrevistas semiestruturadas para coletar os dados, assim como a técnica análise do conteúdo para analisá-los. Como resultados, o estudo revelou que o aplicativo tem potencial pedagógico no ensino de diferentes conteúdos de Biologia, mas sob mediação pedagógica dos professores e por meio de diferentes estratégias de ensino e aprendizagem.
\end{abstract}

Palavras-chave: Whatsapp. Estratégias de ensino. Biologia. Mediação pedagógica. Comunicação.

\section{ABSTRACT}

In cyberculture, the advent of mobile devices altered the forms of communication and interaction. Together with these devices, alternative initiatives for traditional teaching are adopted for more dialogical acts of use and respecting the cultural reality we are experiencing, thus linking formal spaces to informal in a continuous action of teaching and learning. Thus, the role of the teacher and the student's action gains space as communication applications from mobile devices, such as Whatsapp, exploring its multiple screens, weaving new ways to get closer to the students' reality. In this context, the objective of this study was to analyze the pedagogical potential of Whatsapp in the Biology teaching.

Submetido em: 31/03/2020 - Aceito em: 19/05/2020 - Publicado em: 18/08/2020.

${ }^{1}$ Graduado em Ciências Biológicas pela Universidade Federal de Alagoas (UFAL), mestre em Tecnologias da Informação e da Comunicação na Educação (UFAL) e bolsista de doutorado na mesma linha de pesquisa pela Coordenação de Aperfeiçoamento de Pessoal de Nível Superior (CAPES) no Programa de Pós-Graduação em Educação (PPGE) da UFAL.

n.2

p. 21 


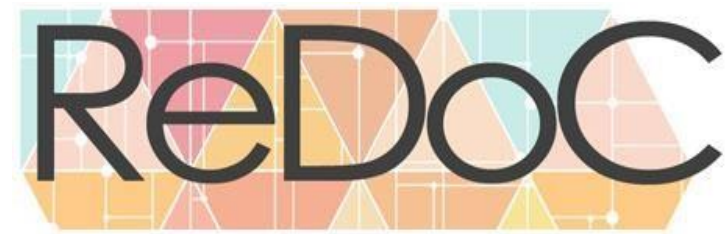

\section{Revista Docência e Cibercultura}

The study hypothesis was that the App has pedagogical potential for teaching subjects that involve this discipline in different contexts and spaces. Two Biology teachers participated of this study. We used semi-structured interviews to collect the data, as well as analysis of the content technique for analysis. As a result, the study revealed that the App has pedagogical potential in teaching different Biology content, but under pedagogical mediation by teachers and through different teaching and learning strategies.

Key-Words: Whatsapp. Teaching strategies. Biology. Pedagogical mediation. Comunication.

\section{RESÚMEN}

En la cibercultura, el advenimiento de los dispositivos móviles ha cambiado las formas de comunicación e interacción. Junto con estos dispositivos, se han tomado iniciativas alternativas a la enseñanza tradicional para enseñar más actos de diálogo y respetar la realidad cultural en la que vivimos, vinculando así los espacios formales e informales en una acción continua de enseñanza y aprendizaje. Por lo tanto, el papel del profesor y la acción de la enseñanza gana espacio a medida que los Apps de comunicación de dispositivos móviles, como Whatsapp, exploran sus múltiples pantallas, tejiendo nuevas formas de acercarse a la realidad de los estudiantes. En este contexto, el objetivo de este estudio fue analizar el potencial pedagógico de Whatsapp en la enseñanza de la Biología. La hipótesis del estudio fue que el App tiene potencial pedagógico para enseñar materias específicas en esta disciplina en diferentes contextos y espacios. Dos profesores de Biología participaron en el estudio. Utilizamos entrevistas semiestructuradas para recopilar los datos, así como la técnica de análisis de contenido para analizarlos. Como resultado, el estudio reveló que el App tiene potencial pedagógico en la enseñanza de diferentes contenidos de Biología, pero bajo la mediación pedagógica de los maestros y a través de diferentes estrategias de enseñanza y aprendizaje.

Palabras Clave: Whatsapp. Estrategias de enseñanza. Biología. Mediación pedagógica. Comunicación.

\section{INTRODUÇÃO}

No contexto da cibercultura, as relações sociais e educacionais sofreram mudanças significativas nos modos de viver, conviver e se comunicar (LÉVY, 1999; MOREIRA; TRINDADE, 2017). Os reflexos dessas mudanças dentro da Educação e de forma mais específica sobre as ações de ensino, confrontam o modelo tradicional de escola sobre o ensinar e aprender, baseado na comunicação unilateral entre professor e seus estudantes (APARICI, 2012). Deste modo, as diferentes redes sociais e aplicativos disponíveis aos jovens e que fazem parte do cotidiano não podem mais ser desconsideradas nos espaços escolares, mas apropriadas por professores em ações de ensino aliadas à sua prática para além dos muros escolares (ALVES et al, 2019; COUTINHO et al, 2016), uma vez que ensinar possibilita a ação criativa dos estudantes (FREIRE, 1996).

Na cibercultura, os aplicativos de comunicação como exemplo do Whatsapp vêm contribuir para redesenhar formas de ensinar e aprender a partir de stories, vídeos, fotografias, áudios, documentos, enfim, hipertextos e telas que se mesclam de forma híbrida (COUTO; SOUZA, 2017; MORAN, 2015; PORTO et al, 2017b). Neste contexto, o problema norteador deste estudo foi: como o aplicativo de comunicação Whatsapp pode ser explorado no contexto de ensino de Biologia? 


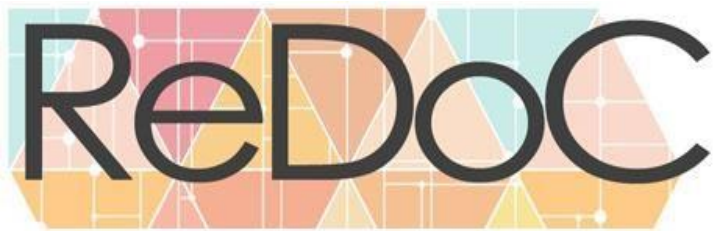

\section{Revista Docência e Cibercultura}

A hipótese que sustentou o estudo foi que o Whatsapp apresenta potencial pedagógico para o ensino de Biologia em diferentes contextos e espaços. O objetivo geral do estudo foi analisar o potencial pedagógico do aplicativo para o ensino de Biologia. Os percursos específicos para alcançar este objetivo maior foram: analisar o aplicativo Whatsapp a partir de um olhar voltado para o ensino de Biologia; identificar as percepções dos professores de Biologia sobre o potencial pedagógico do Whatsapp no ensino da disciplina; comparar os resultados da análise do aplicativo com as percepções trazidas pelos professores de Biologia.

A relevância deste estudo é definida na medida em que, a partir da busca no portal de periódicos da Coordenação de Aperfeiçoamento de Pessoal de Nível Superior (CAPES) de estudos que relacionassem o ensino de Biologia com o aplicativo, nenhum resultado foi encontrado. Neste sentido, este estudo visa contribuir para o preenchimento inicial desta lacuna da literatura.

Em um primeiro momento, iremos analisar a relação entre Educação e Whatsapp em um contexto de cibercultura. Logo em seguida, continuaremos nossa discussão, apresentando o aplicativo como um dos meios de comunicação dialógica entre professores e estudantes. Estudos sobre o tema também serão apresentados, assim como as áreas do conhecimento que têm se debruçado sobre ele. Por último, apresentaremos as trilhas metodológicas e os achados do estudo.

\section{CIBERCULTURA, EDUCAÇÃO E WHATSAPP: CAMINHOS ALTERNATIVOS PARA ENSINAR}

$\mathrm{O}$ advento da internet e o estabelecimento da cibercultura modificaram as formas sobre como pensamos e fazemos educação. Lévy (1999) já preconizava que a chegada dos "telefones móveis" iria revolucionar as formas de comunicação no século XXI. Esses pressupostos do autor são reafirmados quando pensamos nos smartphones atuais. De acordo com Moreira e trindade (2017), as tecnologias móveis estão imersas no cotidiano dos usuários, reformulando as formas que interagimos e nos comunicamos e estes aspectos podem ser aproveitados em contextos educativos a partir do desenvolvimento de estratégias de ensino e aprendizagem. De acordo com Porto et al (2017), para além de aspectos comunicacionais, na cibercultura as práticas envolvem artefatos que permitem novas formas de aprender e de acessar informação, assim como também inovação no ensino. 


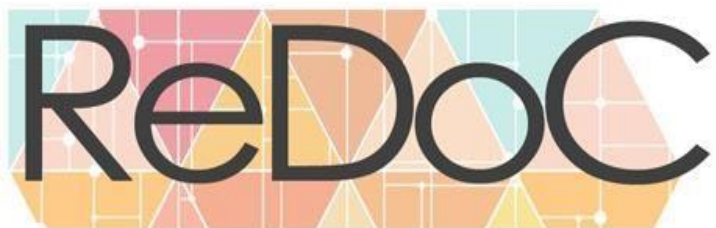

\section{Revista Docência e Cibercultura}

Segundo Alves et al (2019), na cibercultura os dispositivos móveis podem ser incorporados em processos de ensino que fazem parte da realidade dos jovens, sendo uma oportunidade para que professores possam utilizar estas tecnologias atendendo aos anseios dos estudantes. Neste contexto, o "telefone móvel" de Lévy (1999) ganhou espaço dentro e fora da sala de aula e isto pode ser aproveitado em processos de ensino, uma vez que, de acordo com Coutinho et al (2016, p.2) “o estudante contemporâneo demanda um espaço de aprendizagem onde possa existir engajamento, imersão e prazer em aprender. Ele quer ser autor do conhecimento [...] avançando para além de um processo de aprendizagem linear". O aplicativo Whatsapp se configura como um destes espaços (ALVES et al, 2019; AMANDA; FORTANA, 2017; PORTO et al, 2017b).

De acordo com Porto (2017a), estamos cada vez mais conectados no contexto online e dependentes de tecnologias, aplicativos e internet, desenvolvendo modos de existência híbridos. Segundo Moran (2015), na Educação o termo "híbrido" remete a idéia de mistura, mesclado, blended e, realizando um recorte maior, o autor conceitua ensino híbrido, apresentando duas vertentes principais: a primeira compreende o ensino com uso de tecnologias digitais da informação e da comunicação (TDIC) para enriquecer processos de ensino e aprendizagem realizados no contexto presencial e, portanto, baseado em disciplinas; o segundo, por outro lado, aponta para caminhos mais disruptivos em que não existem disciplinas, ocorrendo o uso de múltiplos espaços e metodologias pedagógicas inovadoras. Quando pensamos no primeiro modelo apresentado por Moran (2015), o Whatsapp vem ganhando espaço porque enriquece aulas presenciais uma vez que permite, segundo Porto (2017), trocas de mensagens, imagens, vídeos, documentos e áudios. Coutinho et al (2016, p.5) afirmam que "as possibilidades para o ensino híbrido amplificam-se com o advento dos dispositivos móveis, como tablets e celulares, graças à facilidade de utilizá-los em diferentes ambientes, oportunizando diversas formas e espaços para aprendizagem”. Assim, em um contexto de cibercultura (LÉVY, 1999), ensinar e aprender são processos que vão além de muros escolares.

De acordo com Amante e Fortana (2017, p.136) “o aplicativo Whatsapp constitui-se como uma ferramenta digital espacialmente concebida para dispositivos móveis que permite o envio de mensagens instantâneas (texto, áudio, vídeo, ficheiros diversos) e de chamadas grátis, por meio de chamadas à internet". Neste sentido, configura-se como um aplicativo útil para processos educativos ligados ao ensino (ALVES et al, 2019) e, segundo Coutinho et al (2016, p.3) “aplicativos e os softwares de comunicação instantânea, como o Whatsapp, podem ser ampliados 


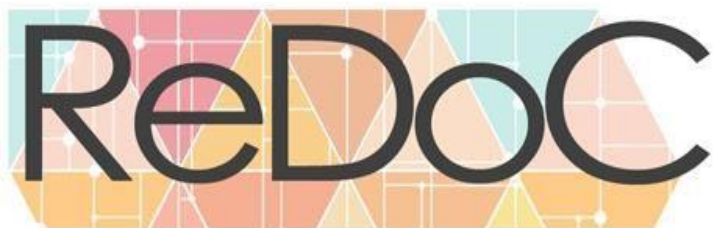

\section{Revista Docência e Cibercultura}

para além da comunicação e entretenimento, avançando no campo da Educação".

No cenário de cibercultura, Alves et al (2019) apontam caminhos sobre como professores podem se apropriar das tecnologias e suas potencialidades pedagógicas nos atos de currículo dentro e fora das escolas, assim como o Whatsapp pode contribuir neste sentido. De acordo com os autores, o aplicativo contribui com processos de ensino e aprendizagem, uma vez que: funciona como um número telefônico, integrando a agenda de contatos existentes, permitindo a criação de grupos de até 256 estudantes em que se pode adicionar foto de perfil em cada um, assim como nomeá-los de acordo com o propósito específico; identificar quem está engajado nas atividades a partir das informações de visualização que fornece (traços cinzas e azuis); visualizar quem está online, digitando ou gravando um áudio e a hora em que o estudante saiu; personalização da comunicação por meio de emojis/emoticons, promovendo a criatividade; acesso a todos documentos no histórico das interações; uso do Whatsapp Web, versão para computadores, facilitando o desenvolvimento de trabalhos em grupos; compartilhamento de documentos em diferentes formatos (pdf; docx; xlsx, etc).

As contribuições práticas do aplicativo se delineiam no campo da leitura e escrita. De acordo com Porto et al (2017b), os processos de leitura e criação de textos no aplicativo permeiam novos caminhos para autoria e produção de conteúdos no contexto digital, típicos da cibercultura, em que são organizados como base no hipertexto, produção e compartilhamento de áudios, vídeos e imagens. Quanto ao hipertexto, os autores discutem sobre como em uma folha de papel a leitura é feita de forma linear, da esquerda para a direita. Contudo, o hipertexto é lido e escrito de forma multilinear, não sequencial, por meio de links que trazem múltiplas telas sem uma ordem predefinida. Adicionalmente, se um texto tradicional apresenta um começo, meio e fim, em um hipertexto quem define o começo é o usuário a partir de um clique em uma imagem, vídeo ou texto e termina quando se fecha o aplicativo ou se finaliza o processo comunicativo com o interlocutor.

Outra funcionalidade disponível pelo Whatsapp para práticas pedagógicas é função stories. De acordo com Couto e Souza (2017, p.152) “a função stories, postagens que em, no máximo, 24 horas deixam de existir nas memórias dos apps, tornou-se a principal atualidade neste contexto e, por isso, foi incorporada a este e outros softwares". Estas postagens permitem que os usuários do Whatsapp possam postar atividades do cotidiano e ainda segundo as autoras são atrativas e se enquadram na velocidade e liquidez da cibercultura, em um fluxo de interação ligado ao tempo presente, do "aqui 


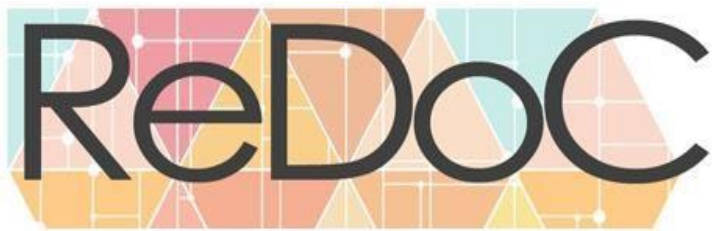

\section{Revista Docência e Cibercultura}

e agora", em um contexto de memória efêmera.

Segundo Amante e Fortana (2017), os dispositivos móveis configuram um novo cenário de ensino e aprendizagem, criando espaços de extensão da sala de aula ao prolongarem discussões e debates sobre temas curriculares a partir da conectividade contínua e a aprendizagem formal com os atores envolvidos, professores e estudantes. Contudo, confrontam os processos educativos e comunicativos da escola em vigor. Na próxima seção, apresentaremos esses principais desafios a serem ainda superados.

\section{WHATSAPP E COMUNICAÇÃO: CONTEXTOS PARA O ENSINO DIALÓGICO E INTERATIVO}

O contexto da cibercultura contrasta com as práticas desenvolvidas no universo escolar tradicional, na medida em que "pensar em tecnologias digitais no cenário escolar significa pensar também o funcionamento da escola. Os recursos tecnológicos estão carregados de valores e tendem a suscitar modos de uso e viver, que se distanciam muito das regras escolares [...]" (COUTINHO et al, 2016,p.8). Aparici (2012) oferece pistas que contrastam estes modos de "uso" e "viver" discutidos por Coutinho et al (2018) ao afirmar que, dentro da sala de aula, os estudantes praticam a cultura oficial, baseada na tradição exclusiva do uso do livro didático, mas fora da instituição escolar a cultura oficial se baseia em um contexto popular e informal em que os estudantes estão imersos nas redes sociais como o Facebook®.

Ainda segundo Aparici (2012), o advento das TDIC e redes sociais tornaram mais visíveis as práticas comunicativas que imperam no ensino da escola tradicional a partir da transmissão e reprodução do conhecimento. Para o autor, em um contexto de aula tradicional os professores agem como se estivessem em um meio de comunicação de massa, assumindo o papel de emissor de informações e, no outro lado, os estudantes assumem o papel de centenas de receptores.

De acordo com Freire (1996, p.21) “ensinar não é transferir conhecimentos, mas criar as possibilidades para a sua própria produção ou a sua construção”. Ao seu tempo, Freire (1996) já enxergava, portanto, a forma em que o ensino considera a autoria dos estudantes, o que a cibercultura atual também proporciona (COUTINHO et al, 2016), assim como também já levantava questões como “por que não estabelecer uma necessária 'intimidade' entre saberes curriculares 


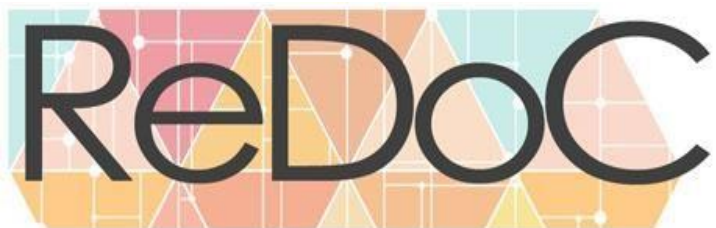

\section{Revista Docência e Cibercultura}

fundamentais aos alunos e as experiência social que eles têm como indivíduos?" (FREIRE, 1996, p.15). O Whatsapp, um aplicativo comunicacional, representa um dos meios de estabelecer ligação entre currículo e ações cotidianas, para além da escola (ALVES et al, 2019). Isso pressupõe "respeitar os saberes dos educandos" (FREIRE, 1996), considerando-os como sujeitos que possuem uma história que não pode ser dissociada da ação de ensinar.

Em contraste com a perspectiva tradicional das escolas problematizada por Aparici (2012), Freire (1996) indica caminhos para pensarmos o ensino sob uma ótica horizontal, indicando passos para que isto aconteça a partir do diálogo. De acordo com Freire (1987, p.46): “o diálogo, como encontro dos homens para a tarefa comum de saber agir, se rompe, se seus pólos (ou um deles), perdem a humildade”. O diálogo rompido é percebido quando escolas pró́bem o uso de telefonia móvel (APARECI, 2012), desconsiderando-a como uma aliada no processo de ensino e aprendizagem. A tarefa comum de "saber agir" preconizada por Freire (1987) não se concretiza nesse cenário da escola tradicional, uma vez que o agir considerado é somente a expertise do professor, excluindo os estudantes do processo dialógico.

A nossa concepção sobre ensino remete às postulados de Tardif (2014, p.118) ao afirmar que “concretamente, ensinar é desencadear uma programação de interações com um grupo de alunos, a fim de atingir determinados objetivos educativos relativos à aprendizagem de conhecimentos e à socialização". Nessa perspectiva de ensino há diálogo e o exercício da criatividade dos estudantes a partir da ação de ensinar conjuntamente com eles e não alheio aos seus anseios (FREIRE, 1987; FREIRE, 1996).

O conceito sobre ensino trazido por Tardif (2014) remete ao cenário interativo proporcionado pelo aplicativo Whatsapp. De acordo com Moreira e Trindade $(2017$, p.58) "o próprio professor, nesse tipo de comunicação digital, que tanto pode funcionar de forma síncrona e assíncrona, reconfigurase com o Whatsapp, sendo o conhecimento construído por todos". Neste contexto, o aplicativo possibilita a criação de um cenário dialógico e próximo à realidade cotidiana dos jovens em que todos participam da ação de ensinar e aprender (FREIRE, 1987; FREIRE, 1996).

Ainda segundo Moreira e Trindade (2017), o aplicativo faz a ponte entre o aprendizado formal dos estudantes e os espaços informais, cotidianos, possibilitando que nas ações do dia a dia, possam construir mais conhecimentos. Nesse processo, segundo as autoras, o professor assume o perfil de "arquiteto" e "construtor" do ambiente de aprendizagem, assumindo o papel de mediador das

v. 4 n.2

p. 27 


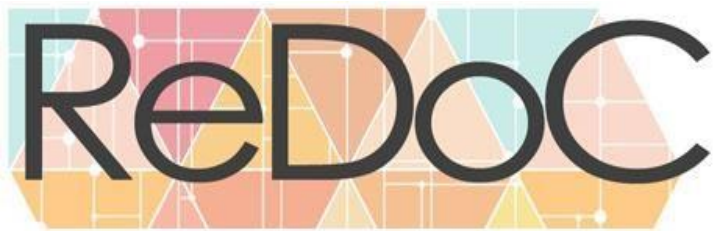

\section{Revista Docência e Cibercultura}

atividades de ensino que serão desenvolvidas de forma dialógica no aplicativo.

A partir do estabelecimento da relação entre a ação de ensinar e Whatsapp, partindo do pressuposto básico de comunicação dialógica, iremos agora analisar alguns trabalhos desenvolvidos com o aplicativo em contextos educativos e o que se tem discutido no campo da Biologia, recorte de interesse deste estudo.

\section{WHATSAPP E ENSINO: TRABALHOS RELACIONADOS}

Os estudos relacionados ao uso do Whatsapp no ensino permeiam a educação básica e o ensino superior e diferentes campos do conhecimento. No contexto do ensino superior, o estudo de Schäfer e Mello (2016) aborda como o aplicativo auxilia o ensino da língua alemã no projeto E-Tutoria, revelando que seu uso contribui para a formação do professor ao se tornar mais seguro na correção de erros na escrita ou fala dos estudantes e que os estudantes no seu percurso formativo nunca haviam interagido no Whatsapp para fins de aprendizagem formal. No ensino médio, o estudo de Coelho e Pinheiro (2017) investigou como o ensino da Língua Espanhola foi mediado pelo Whatsapp de modo a promover a aprendizagem significativa e colaborativa por meio da criação de textos com múltiplas interfaces pelos estudantes, servindo de apoio às aulas presenciais.

O uso do Whatsapp também tem mediado o ensino no contexto da Educação a Distância (EaD). O estudo realizado por Blauth et al (2019), analisou como o Whatsapp pode contribuir no ensino em um contexto em que o aplicativo é utilizado como chat e fórum em uma turma de Pós-Graduação em uma universidade pública. O fórum teve duração de dez dias para interações e o chat teve duração de uma hora. Como resultado, o estudo revelou que o Whatsapp apresenta maior potencial pedagógico a partir do uso do chat, uma vez que no fórum não ocorreu aprofundamento das discussões, ainda que o tutor estivesse mediando o ensino.

O estudo de Buriticá (2018) analisou como o uso do Whatsapp pode contribuir no processo de ensino e aprendizagem de Programação. O estudo foi realizado ao longo de seis semestres com cento e vinte estudantes ao total. $\mathrm{O}$ autor investigou como o seu papel enquanto professor mediador no atendimento e esclarecimento de dúvidas dos estudantes do curso de Programação II de Engenharia de Sistemas e Computação da Universidade Tecnológica de Pereira, Colombia, pode contribuir para aprendizagem dos estudantes que tiveram apoio do Whatsapp durante a disciplina de 


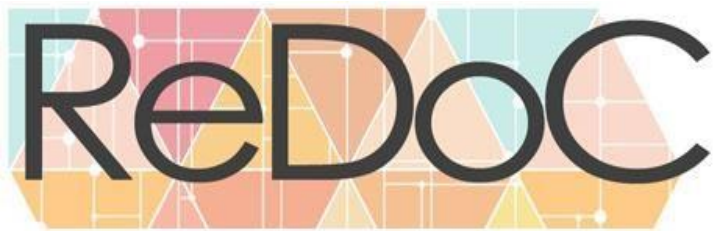

\section{Revista Docência e Cibercultura}

Programação em dentrimento daqueles que não tiveram. Nesse sentido, os estudantes foram divididos a cada semestre em grupos que possuíram apoio pedagógico pelo aplicativo e grupos que não tiveram apoio. Como resultado, ainda que os grupos que tiveram encontros presenciais com o professor da disciplina tenham esclarecido dúvidas e desenvolvido laços afetivos com o docente, os grupos que tiveram apoio com Whatsapp tiveram resultados mais promissores durante o processo de ensino e aprendizagem e nas avaliações finais da disciplina.

O estudo desenvolvido por Moreira e Medeiros (2017) com o uso do Whatsapp no ensino de Química no ensino médio de uma escola pública na Paraíba teve resultados opostos aos que apresentamos até o momento. De acordo com os autores, o uso do aplicativo deve vir acompanhado de mudanças nas práticas pedagógicas desenvolvidas pelo professor. Neste estudo, o Whatsapp assumiu a função de repositório e a desmotivação dos estudantes para aprender foi um dos principais indicadores do insucesso da experiência. A proibição inicial da professora da disciplina sobre "conversas paralelas" dos estudantes no aplicativo pode ter provocado a artificialidade do uso do aplicativo para fins educativos, fugindo do contexto cotidiano de experimentação.

Na Biologia, o trabalho de Azevedo et al (2018) evidenciou o uso do Whatsapp sob a perspectiva de estudantes do ensino médio de uma escola da rede privada do Estado de Sergipe, indicando que o aplicativo pode ser utilizado com a finalidade de esclarecimento de dúvidas a partir da formação de grupos de discussão, mas tendo o cuidado sobre as informações que são postadas e sobre como os estudantes auxiliam uns aos outros nas respostas aos questionamentos, demonstrando que o papel mediador do professor é fundamental para validar as informações científicas que são apresentadas. O estudo de Cunha (2018) envolveu a investigação com professores de Biologia e Ciências a respeito das experiências deles com TDIC e com Whatsapp. No tocante ao aplicativo, os resultados do estudo apontam que ele gera vínculo afetivo, é um espaço de esclarecimento de dúvidas e pesquisas, assim como de compartilhamento de materiais, auxiliando no processo de ensino.

A partir da análise dos trabalhos apresentados, concluímos que o uso do Whatsapp tem permeado diferentes áreas do conhecimento e níveis de ensino. Os estudos desenvolvidos na área de Biologia analisaram as perspectivas dos estudantes a partir de iniciativas dos professores com o aplicativo, mas não focaram na perspectiva docente e de modo específico sobre como ensinar conteúdos desta área do conhecimento a partir do Whatsapp. Neste sentido, nosso recorte visa preencher essa lacuna. Na próxima seção, apresentamos as trilhas metodológicas que orientaram este estudo. 


\section{CAMINHOS METODOLÓGICOS}

Este estudo apresenta abordagem qualitativa com delineamento exploratório. De acordo com Sampieri et al (2013), estudos qualitativos são aqueles que buscam compreender a perspectiva dos participantes, sejam indivíduos ou pequenos grupos de pessoas sobre os fenômenos que as rodeiam, aprofundando suas experiências ou pontos de vista sobre como enxergam subjetivamente a realidade. Strauss e Corbin (2008) acrescentam que são estudos cujos resultados não alcançados por meios estatísticos ou outros meios de quantificação, mas se referem à vida das pessoas, comportamentos, emoções, experiências vividas, etc. Yinn (2016) acrescenta algumas características sobre a abordagem qualitativa, a saber: estuda o significado da vida das pessoas em condições reais; representa opiniões e perspectivas pessoais; abrange condições contextuais em que as pessoas vivem; contribui com revelações sobre conceitos existentes ou emergentes; esforça-se por ter múltiplas fontes de evidência.

De acordo com Sampieri et al (2013), os estudos exploratórios possuem como objetivo examinar um problema de pesquisa pouco estudado e em que há ainda muitas dúvidas a respeito, permitindo que nos familiarizemos com fenômenos relativamente desconhecidos. Neste contexto, a partir de nossa revisão de literatura no portal de periódicos da CAPES, constatamos a ausência de estudos que correlacionassem o ensino de Biologia com o uso do Whatsapp. Realizamos, portanto, uma busca avançada, utilizando a palavra chave "Whatsapp" combinada com a palavra "ensino" ou "Biologia". Mas nenhum resultado na área de Biologia foi encontrado ${ }^{2}$. Neste contexto, investigamos neste estudo o potencial pedagógico do aplicativo Whatsapp para o ensino de Biologia.

Os sujeitos do estudo foram dois professores de Biologia de 28 e 30 anos, identificados neste estudo como professor A e J e atuantes, respectivamente, na rede privada e pública de ensino da cidade de Maceió e que utilizam o aplicativo Whatsapp no cotidiano. Apresentamos aos professores um termo de consentimento livre esclarecido (TCLE) de modo a esclarecer os objetivos do estudo e sobre como eles podem contribuir com o desenvolvimento dele.

\footnotetext{
${ }^{2} \mathrm{O}$ filtro que utilizamos na busca foi: [no título] [é exato] [Whatsapp] [and] [qualquer] [é exato] [Biologia] ou [Ensino]. Selecionamos [somente artigos] e [qualquer data]. A data da última consulta foi 31 de março de 2020.
} 


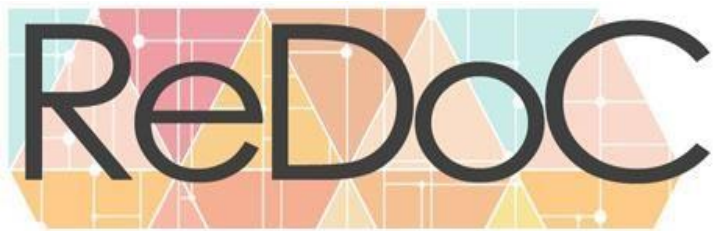

\section{Revista Docência e Cibercultura}

Coletamos os dados por meio de entrevistas semiestruturadas, com duração de uma hora cada uma. Ao transcrevê-las, devolvemos as entrevistas aos sujeitos do estudo de modo verificar se o que disseram correspondiam realmente ao que queriam ter dito, eliminando assim a subjetividade do pesquisador na interpretação dos dados, dando mais confiabilidade neles (SZYMANSKY, 2011).

Utilizamos a técnica análise do conteúdo (BARDIN, 2011), dividida em três etapas: (a) pré-análise: entramos no primeiro contato com os dados brutos e realizamos uma leitura flutuante, tendo as primeiras impressões em torno do material; (b) exploração do material: em que iniciamos o processo de codificação do material, associando os trechos das falas dos sujeitos a categorias de análise definidas previamente; (c) tratamento dos dados obtidos e interpretação: interpretação dos resultados a partir das categorias estabelecidas com os seus respectivos trechos das falas dos sujeitos, chegando a responder ao problema de pesquisa.

As categorias do estudo foram: potencial pedagógico do Whatsapp; estratégias de ensino; mediação pedagógica. Utilizamos o software de análise de dados qualitativos Atlas ti 7® (https://atlasti.com/) para auxiliar na análise do conteúdo dos resultados das entrevistas dos professores.

O estudo foi divido em três etapas: a) análise do aplicativo Whatsapp na modalidade para smartphone e Whatsapp Web para a modalidade computador de mesa e suas potencialidades para o ensino de Biologia; b) identificação das percepções dos professores de Biologia em relação ao potencial pedagógico do aplicativo para ensinar Biologia; (c) comparação dos resultados de nossas impressões em torno do aplicativo com aquelas apresentadas pelos professores.

A partir do delineamento das trilhas metodológicas deste estudo, analisaremos os resultados na próxima seção.

\section{WHATSAPP NO ENSINO DE BIOLOGIA: POTENCIALIDADES PEDAGÓGICAS PARA INTERAÇÕES DIALÓGICAS}

A análise do aplicativo Whatsapp com o olhar voltado para o ensino de Biologia parte do pressuposto de que o pesquisador deste estudo também é licenciado em Ciências Biológicas e possui um arcabouço de conhecimentos da área em questão. Neste contexto, apresentamos os principais resultados e impressões em torno do aplicativo para o ensino de Biologia.

Instalado no celular smartphone, constatamos que o Whatsapp consiste num aplicativo sobre 


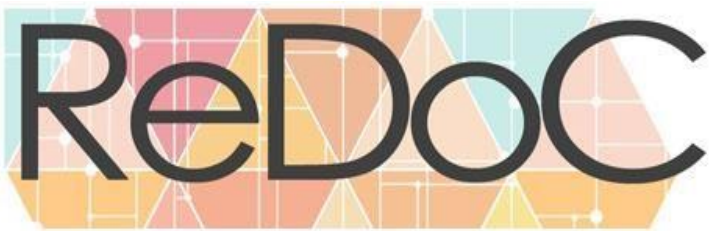

\section{Revista Docência e Cibercultura}

comunicação instantânea e que apresenta diferentes caminhos para propostas pedagógicas, como as apresentadas por Alves et al (2019). De modo específico, para o ensino de Biologia, percebemos que o aplicativo é voltado para o desenvolvimento de atividades de ensino de conteúdos de Ecologia, Zoologia, Botânica e Taxonomia (classificação dos seres vivos). A possibilidade de compartilhar documentos como fotografias e/ou vídeos (AMANTE; FORTANA, 2017) permite pensarmos sobre como os estudantes poderiam registrar o mundo natural e compartilhar os resultados em um grupo que seja criado pelo professor. Essa estratégia de ensino abrange as áreas de Zoologia e Botânica. No campo da Ecologia, assuntos como hábitat (o local em que uma espécie vive) e nicho ecológico (o que a espécie faz/ como interage no meio) podem ser registrados por meio de vídeos: a estratégia seria a gravação, no mundo natural, de espécies de seres vivos em seus hábitats ou realizando seu papel na natureza.

Continuamos nossas análises e, no tocante à Taxonomia, o aplicativo disponibiliza a função de sublinhar palavras ou colocá-las em itálico. Os nomes de espécies são escritos em normas internacionais baseadas em um sistema binominal em que se utiliza o itálico ou sublinhado de forma obrigatória, seguindo os padrões estabelecidos pelo botânico Carlos Lineu (1707-1778): o primeiro nome possui letra maiúscula e o segundo, chamado de epíteto específico, inicial minúscula. Neste sentido, o professor de Biologia ao utilizar o Whatsapp pode desenvolver uma estratégia de ensino em que os estudantes, na vida cotidiana, identifiquem um ser vivo, registrem ele por meio de fotografia ou vídeo, e postem no grupo o nome científico dele utilizando estes elementos gráficos. Para escrever em itálico é necessário utilizar o símbolo _ antes e depois das palavras que se deseja ativar a função. Outro modo de obter o mesmo resultado é pressionar na tela do smartphone a palavra que se deseja colocar em itálico, selecionando-a e, em seguida, clicando no ícone de três pontos que aparece ao lado da palavra "copiar", finalizando assim o processo ao clicar na opção "sublinhar”. A figura 1 exemplifica a situação proposta com o uso do itálico. 


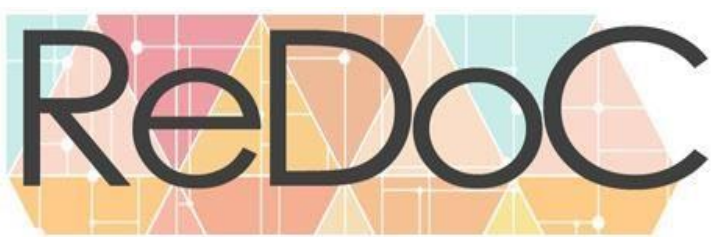

Revista Docência e Cibercultura

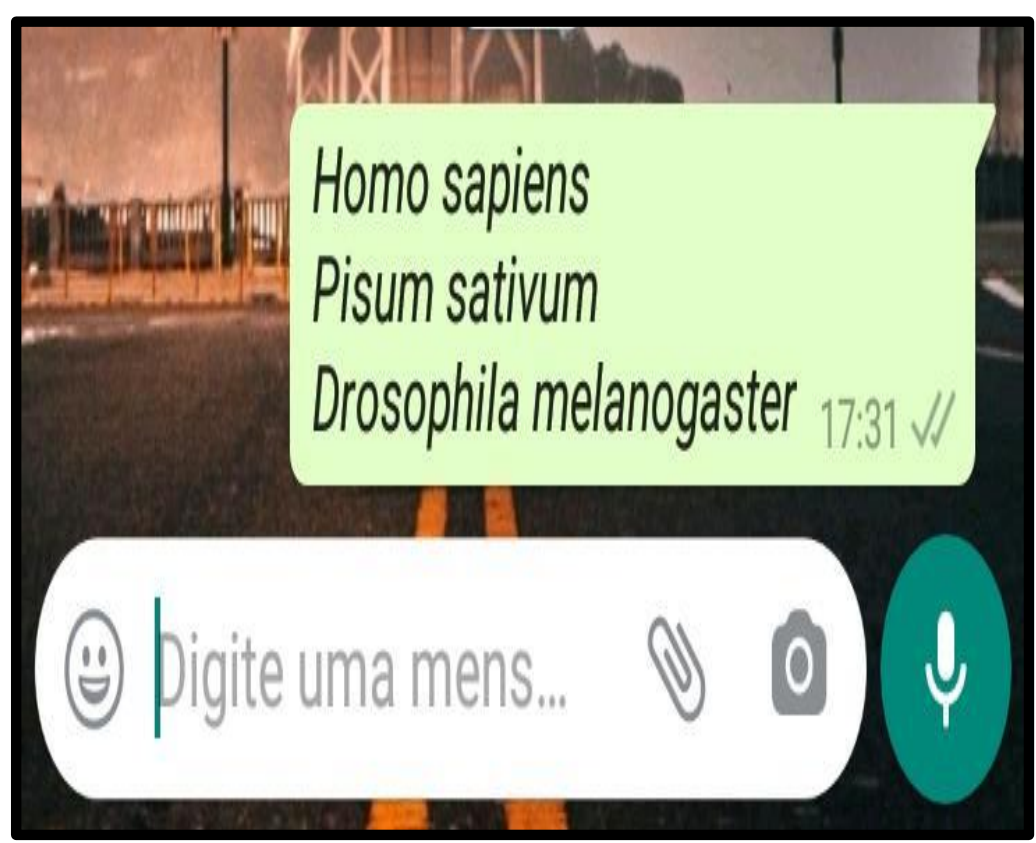

Figura 1: Utilização do recurso itálico para a escrita científica dos nomes de espécies

Fonte: Dados do estudo.

No contexto do ensino de nomeclatura biológica, o professor também pode solicitar a pronúncia dos nomes aos estudantes, uma vez que os mesmos são latinizados. A pronúncia pode ser gravada após a postagem da foto e/ou vídeo do ser vivo registrado, seguida da escrita do nome da espécie. Ao pressionar ícone verde com microfone apresentado na figura 1, o estudante pode fazer gravação de voz para este propósito. Na versão do Whatsapp Web, o ícone é representado por um microfone sem cor.

O uso dos stories pode ser explorado para enviar vídeos ou fotografias sobre o mundo natural, ou algum experimento que o estudante possa estar fazendo, compartilhando com os demais colegas os "momentos" do desenvolvimento da atividade pedagógica. Couto e Souza (2017) ressaltam que esse recurso foca no "aqui e agora". Ele pode ser um dos modos dos professores de Biologia visualizarem o que seus estudantes estão fazendo no momento em termos de atividade proposta para ser desenvolvida em suas residências, mas precisam solicitar previamente a eles que façam postagens nos Status do Whatsapp.

Na escrita, constatamos uma variedade de emoticons ligados à Biologia nas áreas de Zoologia,

\begin{tabular}{l|l|l|l|l|l|l}
\hline (C) Redoc & Rio de Janeiro & v. 4 & n.2 & p. 33 & Maio/Ago 2020 & ISSN 2594-9004 \\
\hline
\end{tabular}




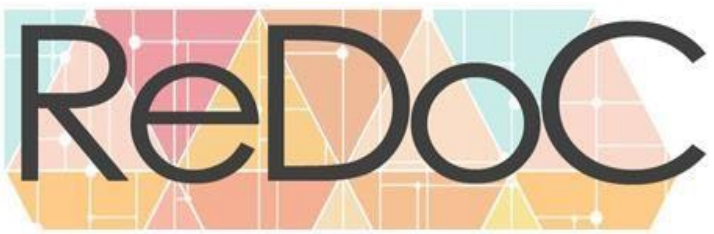

\section{Revista Docência e Cibercultura}

Botânica e Citogenética. A forma de escrita com palavras pode ser combinada com emoticons para fins pedagógicos, a depender da criatividade e proposta do professor. De acordo com Alves et al (2019), a presença dos emoticons permite a personalização da comunicação. Nesta discussão, ela permite que o estudante utilize sua criatividade para comunicar assuntos de interesse biológico, combinando essa representação visual com a forma textual clássica de escrita, mas ao mesmo tempo imersa em uma perspectiva hipertextual (PORTO et al, 2017). A figura 2 exemplifica alguns destes emoticons, disponíveis ao acionar a função teclado do Whatsapp e se procurar na devida seção.

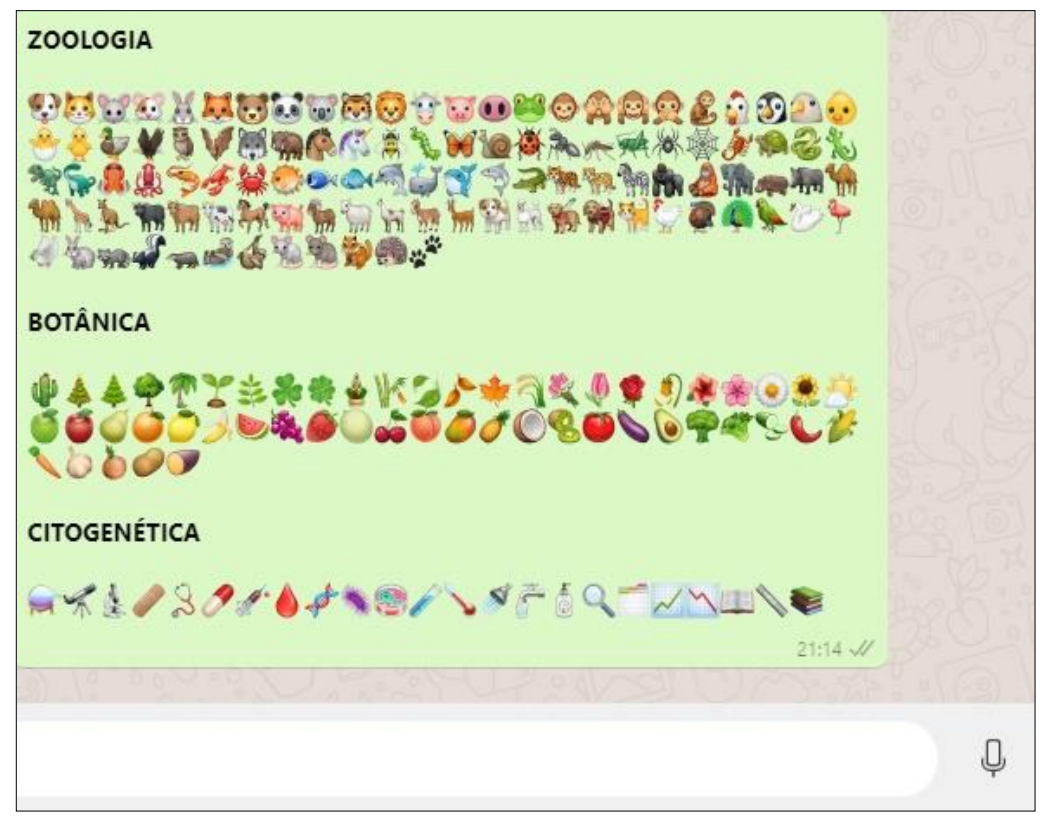

Figura 2- Emoticons ligados à Zoologia, Botânica e Citogenética no Whatsapp App e Web

Fonte: Dados do estudo.

A partir da análise da figura 2, constatamos que a maior quantidade de emoticons está ligada à área de Zoologia e a menor à Citogenética. O professor precisa alinhar esses pressupostos a sua proposta de estratégia de ensino. O uso de emoticons está envolvido com o processo de escrita dos estudantes e isto confronta processos educativos e comunicativos em vigor (AMANTE; FORTANA, 2017).

No tocando ao Whatsapp Web (https://www.whatsapp.com/download), o mesmo apresenta as mesmas funções do aplicativo Whatsapp para smartphones, contudo evidencia a prática colaborativa de realização de atividades em grupo, facilitando principalmente a troca de documentos word e pdf

\begin{tabular}{l|l|l|l|l|l|l}
\hline (C) Redoc & Rio de Janeiro & v. 4 & n.2 & p. 34 & Maio/Ago 2020 & ISSN 2594-9004 \\
\hline
\end{tabular}




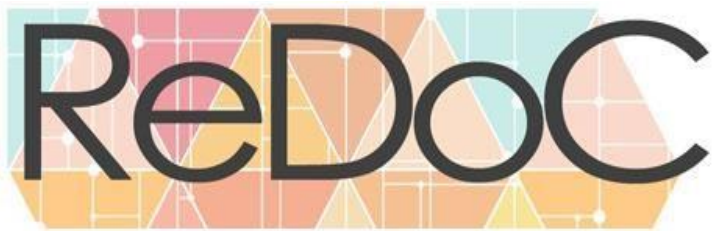

\section{Revista Docência e Cibercultura}

para trabalhos escolares no computador/laptop.

A partir desta análise inicial do aplicativo Whatsapp para o ensino de Biologia, passemos a segunda trilha do estudo: identificar as percepções dos professores de Biologia participantes deste estudo em torno do uso do aplicativo e, por fim, comparar os achados, chegando às conclusões dele.

\subsection{PERCEPÇÕES DE PROFESSORES DE BIOLOGIA SOBRE O POTENCIAL PEDAGÓGICO DO APLICATIVO WHATSAPP PARA O ENSINO}

Ao questionarmos os professores de Biologia se o Whatsapp pode ser explorado em processos de ensino da disciplina, o professor A afirmou que pode ser "adaptado" para este propósito, mas em contextos à distância e que o compartilhamento de diferentes documentos, assim como a organização de grupos menores de até quatro pessoas pode ser útil quando pensamos em videochamadas: no Whatsapp elas podem ser realizadas entre quatro pessoas de uma só vez, o que pode otimizar trabalhos em equipes à distância. Assim, em um contexto de cibercultura (LÉVY, 1999), as formas de comunicação vão além da sala de aula e o aplicativo Whatsapp, segundo Moreira e Trindade (2017), faz parte do cotidiano dos jovens em contextos informais. Nesta perspectiva, o professor A aproveita o viver cotidiano dos estudantes para a continuação da aprendizagem de assuntos iniciados no contexto presencial. O professor $\mathbf{J}$ também pontuou o envio de atividades envolvendo conteúdos de Biologia em um contexto também remoto, acompanhando o estudante para além da sala de aula, assumindo a mesma perspectiva do professor A.

A ênfase do professor A foi que, a partir do uso do Whatsapp, qualquer conteúdo de Biologia pode ser discutido remotamente por meio do compartilhamento de material específico em um grupo que seja formado no aplicativo. Contudo, o professor $\mathrm{J}$ afirmou que áreas como Citologia, Fisiologia, Microbiologia e Ecologia possuem maior potencial para ensinar via Whatsapp. O professor enfatizou as metodologias ativas mediadas pelo aplicativo, como o Estudo de Caso, em que o estudante em equipe precisa resolver um caso que foi criado, e as áreas do conhecimento biológico apontadas pelo professor se articulam diretamente com essa proposta. O professor enfatizou a área de Fisiologia, em que a partir de uma proposta de um caso no grupo do Whatsapp, os estudantes precisariam integrar diferentes conteúdos da Fisiologia para resolvê-lo. No contexto presencial, há a 


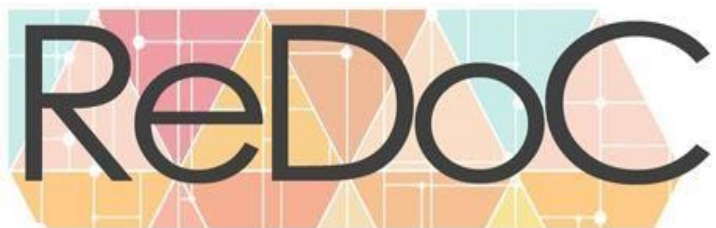

\section{Revista Docência e Cibercultura}

apresentação dos resultados pelos diferentes grupos formados. Assim, o cenário desenhado pelo professor J é de ensino híbrido (MORAN, 2015), enriquecido por meio do whatsapp, uma vez que atividades online ao serem desenvolvidas no aplicativo, irão enriquecer discussões no contexto presencial.

Quanto ao desenvolvimento de estratégias de ensino, o professor A enfatizou a criação de chats coletivos, promovendo debates e discussões sobre temas da área ou "sala" de podcats. A estratégia do uso de chat no Whatsapp já vem sendo evidenciada como promissora, a exemplo do estudo de Blaut et al (2019), sendo esta uma das formas pelo qual o professor A também indica no aproveitamento pedagógico do aplicativo.

Quando questionados sobre a viabilidade pedagógica com Whatsapp em suas escolas a partir do uso de smartphones, ambos professores afirmaram que o uso do celular é permitido, cabendo aos professores apresentarem o planejamento das atividades à gestão pedagógica. Esses dados contrastam com a perspectiva de Aparici (2012) ao exemplificar que existem escolas que proíbem o uso de smartphones. Os exemplos deste estudo indicam que nem todas proíbem e que atividades podem ser desenvolvidas dentro das escolas a partir da apresentação da proposta pedagógica. Na fala do professor $\mathrm{J}$ "eu fico triste quando eu entro numa escola e vejo [cartazes] com aquelas 'marquinhas' num celular com sinal de proibido". Mas o mesmo professor enfatiza que o celular utilizado em sala de aula sem planejamento irá trazer prejuízos, sendo necessário investir em formação pedagógica para esse propósito, possibilitando, assim, a mentoria dos estudantes a partir do uso do celular.

Ao questionarmos aos professores se seus estudantes possuem smartphones, ambos afirmaram que sim, mas nem todos têm permissão para levá-los para escola devido a questões violência na cidade de Maceió. Alves et al (2019) afirmam que os celulares smartphones fazem parte da realidade dos jovens e que isto pode ser aproveitado pelos professores em contextos de ensino. Contudo, este estudo indica que existem eventos contextuais a exemplo da segurança pública que podem impedir que o jovens levem este dispositivo móvel para a escola. O professor A afirmou que wi-fi está disponível em sua escola. O professor J, atuante em escola pública, afirmou que o wi-fi está aberto para professores colocarem notas no sistema acadêmico, mas a sua utilização pelos estudantes é proibida. O professor relata que outros professores propuseram uma atividade com o aplicativo Kahoot (https://kahoot.com/) e eles tiveram que rotear a internet para a turma ou utilizar a estratégia 


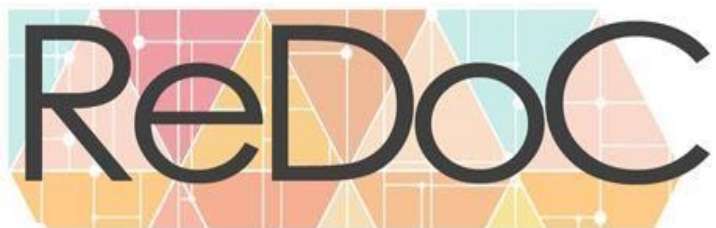

\section{Revista Docência e Cibercultura}

de que os estudantes roteassem a internet uns para os outros.

$\mathrm{O}$ professor A afirmou que em caso de número insuficiente de smartphones por estudantes, uma alternativa seria utilizar a sala de informática para realizar atividades via Whatsapp Web. O professor J, por outro lado, afirmou que o Whatsapp deve sempre ser utilizado de forma remota. Neste contexto, em uma perspectiva de cibercultura existem múltiplas alternativas de acessar informações e aprender (PORTO et al, 2017). Assim, os apontamentos do professor A e J indicam possíveis caminhos para contextualizar o Whatsapp no ensino de Biologia, seja dentro ou fora da escola. O estabelecimento das estratégias de ensino deve, contudo, se consolidar de forma dialógica e construtiva entre os atores do ato educativo (FREIRE, 1987; FREIRE, 1996).

Quando questionamos aos professores se as stories do Whatsapp apresentam potencial pedagógico para o ensino de Biologia, ambos os professores afirmaram que sim. O professor A disse que por meio das stories, os vídeos e imagens criados pelos estudantes poderiam explicar ou conceituar processos biológicos. O professor J propôs que por meio das stories, desafios fossem feitos aos estudantes, indicações de notícias, exercícios de reconhecimento de fakenews e divulgação científica, promovendo assim a cidadania digital dos estudantes. Neste sentido, o uso deste recurso do Whatsapp pode ser estabelecido para que os estudantes registrem como a vida cotidiana, líquida e veloz (AMANTE; FORTANA, 2017) se relaciona com a vida científica e sobre como assuntos como notícias falsas (fake news) também são resultado da efemeridade trazida pela cibercultura, diferenciando assim com a ajuda do professor de Biologia, informações que possuem fundamentos científicos das que não possuem.

Ao questionarmos aos professores se o uso do Whatsapp para fins pedagógicos significa levar mais trabalho para casa, os professores apresentaram as seguintes percepções: o professor A afirmou que seria levar um trabalho "diferente", uma vez que uma questão que ficou mal entendida em sala de aula poderia ser compreendida no contexto à distância, facilitando assim o trabalho presencial. De acordo com Amante e Fortana (2017), os dispositivos móveis criam espaços de extensão em sala de aula, ao se prolongar discussões e debates. Segundo o olhar do professor A, isto significa facilitar o trabalho no contexto presencial, porque dúvidas podem ser sanadas previamente ao encontro presencial via Whatsapp. O professor $\mathrm{J}$ afirmou que professores já levam trabalho para casa, e pensar em Whatsapp é pensar que trabalho burocrático seja diminuído ao enxergarmos o aplicativo como um meio que pode já avaliar os estudantes. Contudo, sob a ótica do professor, acompanhar os 


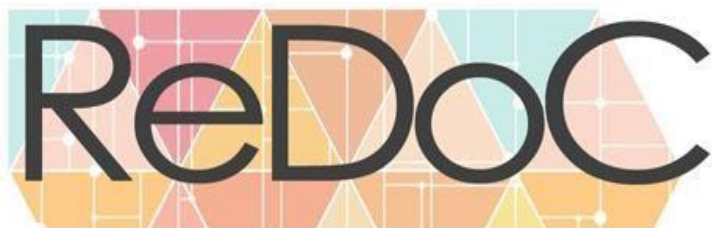

\section{Revista Docência e Cibercultura}

estudantes à distância dá trabalho, exigindo planejamento e regras de interação nos grupos. Deste modo, quando pensamos em interações entre estudantes o conceito sobre ensino trazido por Tardif (2014) permite o desencadear de interações dos estudantes no Whatsapp, mas segundo o professor J, são necessárias regras para estabelecer como essas interações ocorrerão.

Por último, ao questionarmos os professores se o uso do Whatsapp serve como veículo mediação da aprendizagem dos estudantes ou como meio pelo qual os estudantes podem aprender por conta própria, os professores divergiram suas percepções. Na visão do professor A, a tecnologia e internet possibilitaram o acesso a inúmeras informações. Assim, se não houver direcionamento, estas informações podem ficar avulsas e não correspondendo ao rigor científico. O professor conclui que o aplicativo serve como recurso metodológico para mediar o ensino. O professor J, por outro lado, afirmou que o Whatsapp serve inicialmente como um instrumento mediador em que o professor pode conduzir os estudantes com base nos conteúdos que disponibiliza nos grupos. Contudo, o professor $\mathbf{J}$ ainda explica que à medida que o tempo vai passando, o estudante vai realizar buscas para além do Whatsapp, outras informações e fontes de conteúdos, assumindo assim sua autonomia. O Youtube foi mencionado como um dos meios alternativos para busca individual dos estudantes. Logo, em um contexto de cibercultura (LÉVY, 1999), aprender vai além da sala de aula e permeia diferentes espaços. O Whatsapp representa um dos meios em que ações de ensinar vão além de um espaço físico limitado como a escola, unindo o ensino formal com o informal, cotidiano, em que o professor assume o papel de "arquiteto" na construção de grupos no aplicativo e medeia o processo de ensino e aprendizagem (MOREIRA; TRINDADE, 2017).

\section{CONSIDERAÇÕES FINAIS}

A partir da análise do aplicativo Whatsapp, das percepções dos professores de Biologia em torno do potencial pedagógico do aplicativo e da comparação dos resultados, concluímos que a hipótese deste estudo foi confirmada: o aplicativo Whatsapp possui potencial pedagógico para o ensino de Biologia. A partir da comparação dos resultados, concluímos que o potencial pedagógico do aplicativo é voltado para diferentes áreas do conhecimento biológico (Zoologia, Botânica, Citogenética, Microbiologia, Fisiologia, etc), mas sob mediação pedagógica do professor conduzindo o processo de ensino e aprendizagem. 


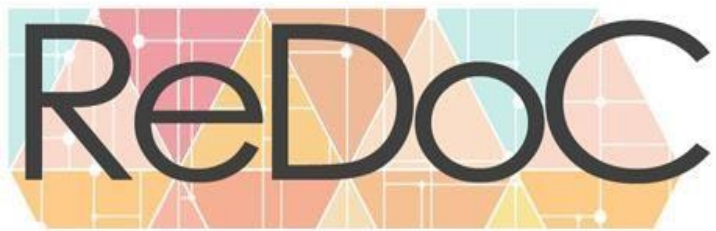

\section{Revista Docência e Cibercultura}

$\mathrm{O}$ estudo revelou que as escolas dos professores possuem wi-fi e que seus estudantes majoritariamente têm celulares smartphones, contudo a falta de segurança na cidade de Maceió e a burocracia das escolas podem ser desafios que ainda precisam ser superados para que práticas com o aplicativo sejam desenvolvidas dentro destas instituições. O professor A indicou o uso do Whatsapp Web na sala de informática em caso de número insuficiente de dispositivos. Isto indica que no contexto de cibercultura, mesmo em meio a dificuldades, existem caminhos alternativos para ação docente.

Os resultados das falas dos professores também apresentaram diferentes maneiras de aproveitar os recursos que o Whatsapp possui: stories, grupos, vídeos, áudios e documentos. Contudo, os mesmos não mencionaram os emoticons e sobre como eles podem se integrar ao processo de escrita a partir das interações nos grupos, o que a análise do aplicativo revelou como sendo um possível caminho a ser trilhado por professores de Biologia. A análise do aplicativo também indicou que a partir da função itálico o ensino sobre nomenclatura científica de espécies se integra com outros recursos que o aplicativo possui, como a possibilidade de envio de fotografias e/ou vídeos.

A partir de nosso resgate de literatura, indicamos o desenvolvimento de trabalhos empíricos com o Whatsapp no ensino de Biologia, uma vez que nenhum estudo que integrasse essa área do conhecimento com o aplicativo foi encontrado no portal de periódicos CAPES.

Em um contexto de cibercultura, concluímos que o Whatsapp faz parte do cotidiano das pessoas, estando em diferentes tempos e espaços. Os professores, portanto, em um contexto dialógico com seus estudantes podem mediar vivências significativas deles por meio do Whatsapp, seja dentro ou para além dos muros escolares.

\section{REFERÊNCIAS}

ALVES, André L.; PORTO, Cristiane.; OLIVEIRA, Kaio E. Educação mediada pelo whatsapp: uma experiência com jovens universitários. In: SANTOS, Edméa.; PORTO, Cristiane (org.). AppEducation: fundamentos, contextos e práticas educativas luso-brasileiras na cibercultura. Salvador: Edufba, 2019.p.221-240.

APARICI, Roberto. Conectividade no ciberespaço. In: APARICI, Roberto (org.). Conectados no ciberespaço. São Paulo: Paulinas, 2012. p.5-24.

AZEVEDO, Maria M.; SOUZA, Adriana A.; REIS, Letícia M. O whatsapp no processo de ensino e 


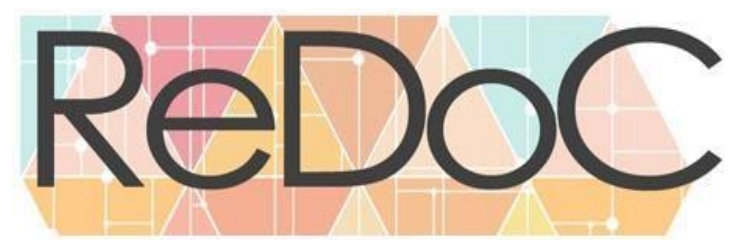

\section{Revista Docência e Cibercultura}

aprendizagem de Biologia. In: Encontro Internacional de Formação de Professores,8.; Fórum Permanente de Inovação Educacional, 9., Aracaju, SE, 2018. Anais eletrônicos...Aracaju,SE: UNIT, 11 a 12 mar. 2018. Disponível em:

<https://eventos.set.edu.br/index.php/enfope/issue/view/17/showToc > Acesso em: 27 mar.2020.

BARDIN, Laurence. Análise de conteúdo. São Paulo: Edições 70, 2011.

BLAUTH, Ivanete.; DIAS, Nelson.; CHERER, Suely. Whatsapp como ambiente de interações na educação a distância: ensaios de encontros síncronos e assíncronos. Holos, Ano 35, v.6, 2019, p.113. Disponível em: 〈http://www2.ifrn.edu.br/ojs/index.php/HOLOS/article/view/6298> Acesso em: 27 mar.2020.

BURITICÁ,Omar I. Whatsapp como herramienta de apoyo al proceso de enseñanza y aprendizage de la programación de computadores. Educación y Ciudad. n.35, 2018, p.149-158. Disponível em: <https://dialnet.unirioja.es/servlet/articulo?codigo=6702430 $>$ Acesso em: 27.mar.2020.

COELHO, Iandra M.; PINHEIRO, Márcia L. As contribuições do Whatsapp no ensino de espanhol: uma perspectiva de aprendizagem significativa e colaborativa. Revista Ibero-Americana de Estudos em Educação. v.12, n.esp.2, 2017, p.1287-1312. Disponível em:

<https://periodicos.fclar.unesp.br/iberoamericana/article/view/10298> Acesso em: 27 mar.2020.

COUTINHO, Isa J.; RODRIGUES, Patrícia R.; ALVES, Lynn. Jogos eletrônicos, redes sociais e dispositivos móveis: reflexões sobre espaços educativos. Obra Digital. n.10, 2016, p.1-12.

Disponível em: 〈http://revistesdigitals.uvic.cat/index.php/obradigital/article/view/76> Acesso em:

28 mar.2020.

COUTO, Edvaldo S.; SOUZA, Joana D. Whatsapp com função stories: ensinar e aprender na magia do instante. In: PORTO, Cristiane.; OLVIEIRA, Kaio E.; CHAGAS, Alexandre (org.). Whatsapp e Educação: entre mensagens, imagens e sons. Salvador: Edufba, 2017. p.151-168.

CUNHA, Camila. As tecnologias da informação e comunicação (TIC): concepções e experiências de professores sobre aplicativo whatsapp no ensino de Ciências e Biologia.In: Encontro Internacional de Formação de Professores,8.; Fórum Permanente de Inovação Educacional, 9., Aracaju, SE, 2018 Anais eletrônicos...Aracaju, SE: UNIT, 11 a 12 mar. 2018. Disponível em: <https://eventos.set.edu.br/index.php/enfope/issue/view/17/showToc> Acesso em: 27 mar.2020.

FREIRE, Paulo. Pedagogia do oprimido. 17ed. Rio de Janeiro: Paz\&Terra, 1987.

FREIRE, Paulo. Pedagogia da autonomia: saberes necessários à prática educativa. 25ed. São Paulo: Paz\&Terra, 1996.

LÉVY, Pierre. Cibercultura. São Paulo: editora 34, 1999.

MORAN, José. Educação híbrida: um conceito chave para a educação, hoje. In: BACICH, Lilian.; 


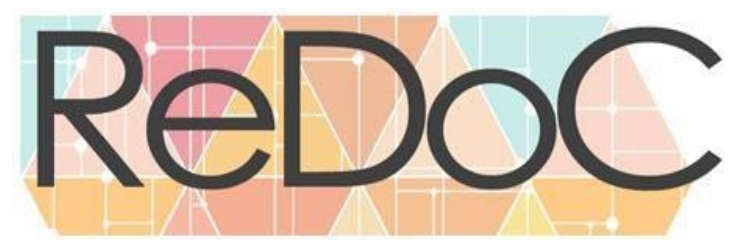

\section{Revista Docência e Cibercultura}

TANZI NETO, Adolfo; TREVISANI, Fernando M (org.). Ensino híbrido: personalizando a tecnologia na educação. Porto Alegre: Penso, 2015, p.27-46.

MOREIRA, Michele L.; MEDEIROS, Anderson S. O uso do whatsapp como ferramenta pedagógica no ensino de Química. ACTIO: Docência em Ciências, Curitiba, v.2, n.3, 2017, p.2143. Disponível em: 〈https://periodicos.utfpr.edu.br/actio/article/view/6905> Acesso em: 28 mar.2020.

MOREIRA, Antonio.; TRINDADE, Sara D. Whatsapp como dispositivo pedagógico para a criação de ecossistemas educomunicativos. In: PORTO, Cristiane.; OLVIEIRA, Kaio E.; CHAGAS, Alexandre (org.). Whatsapp e Educação: entre mensagens, imagens e sons. Salvador: Ilhéus, 2017. p.49-68.

PORTO, Cristiane M.; OLIVEIRA, Kaio E.; CHAGAS, Alexandre. Educação e whatsapp: ensinar e aprender por mensagens instantâneas. In:PORTO, Cristiane.; OLVIEIRA, Kaio E.; CHAGAS, Alexandre (org.). Whatsapp e Educação: entre mensagens, imagens e sons. Salvador: Ilhéus, 2017a.p.9-14.

PORTO, Cristiane M.; OLIVEIRA, Kaio E.; ALVES, André L. Expansão e reconfigurações das práticas de leitura e escrita por meio do whatassap. In:PORTO, Cristiane.; OLVIEIRA, Kaio E.; CHAGAS, Alexandre (org.). Whatsapp e Educação: entre mensagens, imagens e sons. Salvador: Ilhéus, 2017b.p.113-128.

SAMPIERI, Roberto H.; COLLADO, Carlos F.; LUCIO, María P. Metodologia de pesquisa. 5ed. Porto Alegre: Penso, 2013.

SCHÄFER, Gabriela M.; MELLO, Deborah. Ações e reflexões sobre o uso de um grupo de Whatsapp tutoriado para a aprendizagem de língua estrangeira. Entrelínguas, Araraquara, v.2, n.2, 2016, p.163-178. Disponível em: 〈https://periodicos.fclar.unesp.br/entrelinguas/article/view/8493> Acesso em: 27 mar.2020.

STRAUSS, Anselm.; CORBIN, Juliet. Pesquisa qualitativa: técnicas e procedimentos de teoria fundamentada. 2ed. Porto Alegre: Artmed, 2008.

SZYMANSKY, Heloisa. Entrevista reflexiva: um olhar psicológico sobre a entrevista em pesquisa. In: SZYMANSKY, Heloisa.; ALMEIDA, Laurinda R.; PRANDINI, Regina C. (org.). A entrevista na pesquisa em Educação: a prática reflexiva. Brasília: Liber Livro, 2011, p.9-61.

TARDIF, Maurice. Saberes docentes e formação profissional. 17ed. Petrópolis: Vozes, 2014.

YINN, Robert K. Pesquisa qualitativa do início ao fim. Porto Alegre: Penso, 2016. 


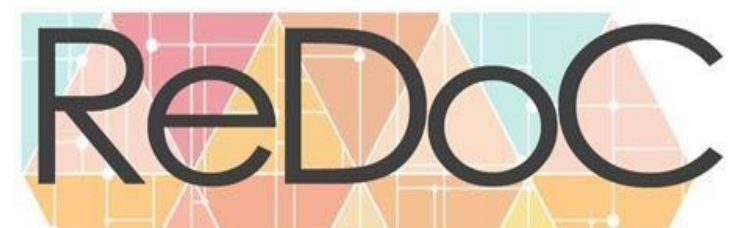

Revista Docência e Cibercultura

\section{AGRADECIMENTOS}

O presente trabalho foi realizado com apoio da Coordenação de Aperfeiçoamento de Pessoal de Nível Superior- Brasil (CAPES)- Código de financiamento 001.

Este é um artigo de acesso aberto distribuído sob os termos da Licença Creative Commons Atribuição Não Comercial-Compartilha Igual (CC BY-NC- 4.0), que permite uso, distribuição e reprodução para fins não comerciais, com a citação dos autores e da fonte original e sob a mesma licença. 